Article

\title{
Entropy Generation in a Dissipative Nanofluid Flow under the Influence of Magnetic Dissipation and Transpiration
}

\author{
Dianchen Lu ${ }^{1}$,, Muhammad Idrees Afridi ${ }^{2}$, Usman Allauddin ${ }^{3}$, Umer Farooq $^{1}{ }^{1}$ \\ and Muhammad Qasim 1,* \\ 1 Department of Mathematics, Faculty of Science, Jiangsu University, Zhenjiang 212013, China; \\ dclu@ujs.edu.cn (D.L.); umer_farooq@comsats.edu.pk (U.F.) \\ 2 Department of Computing, Abasyn University, Islamabad 45710, Pakistan; \\ Muhammad.idrees@abasynisb.edu.pk \\ 3 Department of Mechanical Engineering, NED University of Engineering \& Technology, \\ Karachi 75270, Pakistan; usman.allauddin@neduet.edu.pk \\ * Correspondence: mqasim@ujs.edu.cn
}

Received: 18 June 2020; Accepted: 25 August 2020; Published: 21 October 2020

\begin{abstract}
The present study explores the entropy generation, flow, and heat transfer characteristics of a dissipative nanofluid in the presence of transpiration effects at the boundary. The non-isothermal boundary conditions are taken into consideration to guarantee self-similar solutions. The electrically conducting nanofluid flow is influenced by a magnetic field of constant strength. The ultrafine particles (nanoparticles of $\mathrm{Fe}_{3} \mathrm{O}_{4} / \mathrm{CuO}$ ) are dispersed in the technological fluid water $\left(\mathrm{H}_{2} \mathrm{O}\right)$. Both the base fluid and the nanofluid have the same bulk velocity and are assumed to be in thermal equilibrium. Tiwari and Dass's idea is used for the mathematical modeling of the problem. Furthermore, the ultrafine particles are supposed to be spherical, and Maxwell Garnett's model is used for the effective thermal conductivity of the nanofluid. Closed-form solutions are derived for boundary layer momentum and energy equations. These solutions are then utilized to access the entropy generation and the irreversibility parameter. The relative importance of different sources of entropy generation in the boundary layer is discussed through various graphs. The effects of space free physical parameters such as mass suction parameter $(S)$, viscous dissipation parameter $(E c)$, magnetic heating parameter $(M)$, and solid volume fraction $(\phi)$ of the ultrafine particles on the velocity, Bejan number, temperature, and entropy generation are elaborated through various graphs. It is found that the parabolic wall temperature facilitates similarity transformations so that self-similar equations can be achieved in the presence of viscous dissipation. It is observed that the entropy generation number is an increasing function of the Eckert number and solid volume fraction. The entropy production rate in the $\mathrm{Fe}_{3} \mathrm{O}_{4}-\mathrm{H}_{2} \mathrm{O}$ nanofluid is higher than that in the $\mathrm{CuO}-\mathrm{H}_{2} \mathrm{O}$ nanofluid under the same circumstances.
\end{abstract}

Keywords: nanofluid; heat transfer; entropy generation; viscous dissipation; magnetic heating

\section{Introduction}

The Navier-Stokes equations, which are second-order nonlinear partial differential equations, govern the viscous fluid-fluid flow. The exact solution of the complete Navier-Stokes equations has not yet been computed. However, closed-form solutions can be established in certain physical circumstances under reasonable suppositions [1-5]. Exact solutions are important since such solutions can be utilized to validate asymptotic analytical and numerical solutions. Crane [6] found the closed-form solution of the simplified Navier-Stokes equations under the boundary layer approximations to analyze the flow 
over a stretched surface. Some researchers determined the closed-form solutions of boundary layer flow after the pioneering work of Crane with various physical conditions [7-11].

It is essential to examine heat transfer issues in industrial engineering. Recently, heat transfer analysis has been limited to the first law of thermodynamics, which only concerns energy conservation during the interactions of the systems and surroundings. It deals solely with the amount of energy regardless of its quality. Moreover, the first law does not distinguish between heat and work. It assumes that work and heat are fully interchangeable, but work is high-quality energy and can be fully converted into heat, while heat is low-quality energy and cannot be fully converted into work. Heat is an unorganized form of energy. The law of entropy shows that the entropy increase in the cold object is higher than the decrease of entropy in the hot object. This means that the final state is more random in the thermodynamic system. This analysis suggests that the heat transfer phenomenon decreases energy quality or increases the system entropy. To investigate this energy quality reduction, Bejan [12,13] proposed a method called entropy minimization that is based on the law of entropy. The law of entropy (second law of thermodynamics) is used to maintain energy quality [14-20]. In addition to heat transfer, frictional heating and magnetic dissipation also generate entropy in fluid flow problems [21-25].

Conventional working fluids such as kerosene, gasoline, water, engine oil, and fluid mixtures have exceptionally poor thermal conductivity, as demonstrated by the vast number of industries dealing with these conventional working fluids. However, due to their inefficiency in thermal conductivity, they face several problems. The use of nanoscale elements in base fluids is one of the most important techniques used to resolve this deficiency. Such a mixture of nanometer-sized particles and a working fluid is called a nanofluid. In comparison to base liquids, nanofluids possess high thermal conductivity [26-32]. Many researchers firmly agree on the remarkable characteristics of nanofluids. Over the past two decades, this new type of fluid has attracted the attention of many researchers. Nanofluid studies have a variety of important applications, such as product provision for cancer, cooling systems, nuclear power plant cooling, and computer equipment cooling. Hsiao [33] conducted stagnation nanofluid energy conversion analysis for the conjugate problem of conduction-convection and heat source/sink. Ma et al. [34] explored the gravitational convection term of heat management in a shell and tube heat exchanger filled with a $\mathrm{Fe}_{3} \mathrm{O}_{4}-\mathrm{H}_{2} \mathrm{O}$ nanoliquid by utilizing a lattice Boltzmann scheme. Wakif et al. [35] reported the impacts of thermal radiation and surface roughness on the complex dynamics of water transporting alumina and copper oxide nanoparticles. Hsiao [36] reported nanofluid flow for conjugating mixed convection and radiation with interactive physical characteristics. In a channel with active heaters and coolers, a numerical simulation was introduced by $\mathrm{Ma}$ et al. [37] to examine the impacts of magnetic field on heat transfer in a $\mathrm{MgO}-\mathrm{Ag}-\mathrm{H}_{2} \mathrm{O}$ nanoliquid. Prasad et al. [38] examined the upper-convected Maxwell three-dimensional rotational flow with a convective boundary condition and zero mass flux for the concentration of nanoparticles. Frictional heating is the conversion of fluid kinetic energy to heat due to the frictional forces between all the neighboring fluid layers. Frictional heating is the main factor in the study of heat transfer in boundary layer flows. Since large velocity gradients exist within the boundary layer, the viscous dissipation effects cannot be neglected. When there is a viscous dissipation, a term for viscous dissipation is incorporated into the energy equation [39-46].

In this research, the exact solutions of transformed nonlinear dimensionless momentum and energy equations that occur in the magnetohydrodynamic (MHD) boundary layer flow of nanofluid are obtained. The goal of the work, apart from providing a benchmark solution for numerical simulation, is the parametric analysis of entropy generation. The work also describes how boundary conditions facilitate similarity transformations to get self-similar equations. The literature review reveals that nonsimilar problems are treated as self-similar problems. Furthermore, the entropy generation analysis exists in literature, but the analysis is limited to the low temperature difference between the boundary and bulk fluid. The present work is free from such a constraint and is valid for both low and high temperature differences. In addition, the terms for frictional heating and magnetic dissipation are 
added to the energy equation and the expression for entropy generation. To the best of our knowledge, no one has reported the exact solutions for nanofluid flow induced by a linearly stretching surface with a parabolic temperature profile at the boundary. Obtained exact solutions are used for calculating entropy generation and the Bejan number. Visual representations are used to investigate the effects of physical parameters on the nanofluid flow, thermal field, entropy generation profile, and Bejan number.

\section{Statement of the Problem and Governing Equations}

Consider the electrically conducting and dissipative nanofluid flow over a stretching surface as shown in Figure 1. The nanofluid is supposed to be a mixture of base fluid (water) and nanoparticles $\mathrm{Fe}_{3} \mathrm{O}_{4} / \mathrm{CuO}$. The Cartesian coordinate system $(X, Y)$ is chosen in such a way that the $X-$ axis is taken along the solid boundary and the $Y-$ axis is normal to it. Let $U_{w}(X)=U_{0} X$ be the velocity of the stretching boundary and $T_{w}(X)=T_{b}+C_{o} X^{2}$ be the temperature variation at the surface of the stretching boundary; here, $T_{b}$ and the subscript $w$ represent the bulk fluid temperature and the condition at the solid boundary, while $U_{o}$ and $C_{o}$ represent the dimensional constants. The imposed magnetic field is constant and of strength $B_{0}$. The generalized Ohm's law in the absence of an electrical field is $\vec{j}=\sigma_{n f}\left(\vec{q} \times \vec{B}_{o}\right)$, where $\sigma_{n f}$ and $\vec{q}(\vec{U}, \vec{V})$ show the electrical conductivity of nanofluid and bulk velocity field of the nanofluid, respectively. The magnetic force $\bar{j} \times B_{0}$ and magnetic dissipation $\frac{\vec{j} \cdot \vec{j}}{\sigma_{n f}}$ are simplified to $-\sigma_{n f} B_{o}^{2} U$ and $\sigma_{n f} B_{o}^{2} U^{2}$, respectively.

The equations governing the incompressible nanofluid flow for the present problem are

$$
\begin{gathered}
\frac{\partial U}{\partial X}+\frac{\partial V}{\partial Y}=0 \\
U \frac{\partial U}{\partial X}+V \frac{\partial U}{\partial Y}=v_{n f} \frac{\partial^{2} U}{\partial Y^{2}}-\frac{\sigma_{n f} B_{o}^{2} U}{\rho_{n f}}, \\
\left(U \frac{\partial T}{\partial X}+V \frac{\partial T}{\partial Y}\right)=\left(\frac{1}{\rho C_{p}}\right)_{n f}\left(k_{n f} \frac{\partial^{2} T}{\partial Y^{2}}+\mu_{n f}\left(\frac{\partial U}{\partial Y}\right)^{2}+\sigma_{n f} B_{o}^{2} U^{2}\right)
\end{gathered}
$$

The imposed boundary conditions are as follows:

$$
\left.\begin{array}{c}
U(X, 0)=\mathrm{U}_{w}(X)=U_{0} X, \mathrm{~V}(X, 0)=V_{w}, T(X, 0)=T_{w}(X)=T_{b}+C_{o} X^{2} \\
U(X, Y \rightarrow \infty) \rightarrow 0, T(X, Y \rightarrow \infty) \rightarrow T_{b}
\end{array}\right\}
$$

The governing self-similar equations are obtained from Equations (2) and (3) by using the following dimensionless variables:

$$
\eta=Y \sqrt{\frac{U_{o}}{v_{b f}}}, U=U_{o} X f^{\prime}(\eta), V=-\sqrt{U_{o} v_{b f}} f(\eta), \theta(\eta)=\frac{T-T_{b}}{T(X, 0)-T_{b}}
$$

Equations (2) and (3) under the transformation in Equation (5) become

$$
\begin{gathered}
\frac{G_{1}}{G_{0}} f^{\prime \prime \prime}+f f^{\prime \prime}-f^{\prime 2}-\frac{G_{3}}{G_{0}} M^{2} f^{\prime}=0, \\
\frac{G_{5}}{G_{4}} \theta^{\prime \prime}+\frac{G_{1}}{G_{4}} E c \operatorname{Pr} f^{\prime \prime 2}+\operatorname{Pr} f \theta^{\prime}+\frac{G_{3}}{G_{4}} E c M^{2} \operatorname{Pr} f^{\prime 2}-2 \operatorname{Pr} \theta f^{\prime}=0
\end{gathered}
$$

The imposed boundary conditions are transformed to

$$
f(0)=-\frac{V_{w}}{\sqrt{U_{o} v_{b f}}}=S, f^{\prime}(0)=1, f^{\prime}(\eta \rightarrow \infty)=0
$$




$$
\theta(0)=1, \theta(\eta \rightarrow \infty)=0
$$

where $G_{0}=(1-\phi)+\phi\left(\frac{\rho_{s}}{\rho_{b f}}\right), G_{1}=(1-\phi)^{-2.5}, G_{3}=\frac{\sigma_{n f}}{\sigma_{b f}}, G_{4}=1-\phi+\phi\left(\frac{\left(\rho C_{p}\right)_{s}}{\left(\rho C_{p}\right)_{b f}}\right), G_{5}=\frac{k_{n f}}{k_{b f}}$, and $E c=\frac{U_{w}^{2}}{\left(C_{p}\right)_{b f}\left(T(X, 0)-T_{b}\right)}$ (Eckert number), and the subscripts $b f$ and $s$ are used for base fluid and nanoparticles, respectively. $\operatorname{Pr}=\frac{v_{b f}}{\alpha_{b f}}$ (Prandtl number); $\alpha_{b f}$ indicates base fluid thermal diffusivity; $M^{2}=\frac{\sigma_{b f} B_{o}^{2}}{\rho_{b f} U_{0}} ; S=-\frac{V_{w}}{\sqrt{U_{o} v_{b f}}}$ and shows the dimensionless mass-transfer parameter; and $v_{n f}, \sigma_{n f}, \rho_{n f}, k_{n f}$, and $\left(\rho C_{p}\right)_{n f}$ are defined in Table 1. The thermophysical properties of $\mathrm{CuO}, \mathrm{Fe}_{3} \mathrm{O}_{4}$, and working fluid $\left(\mathrm{H}_{2} \mathrm{O}\right)$ are shown in Table 2.

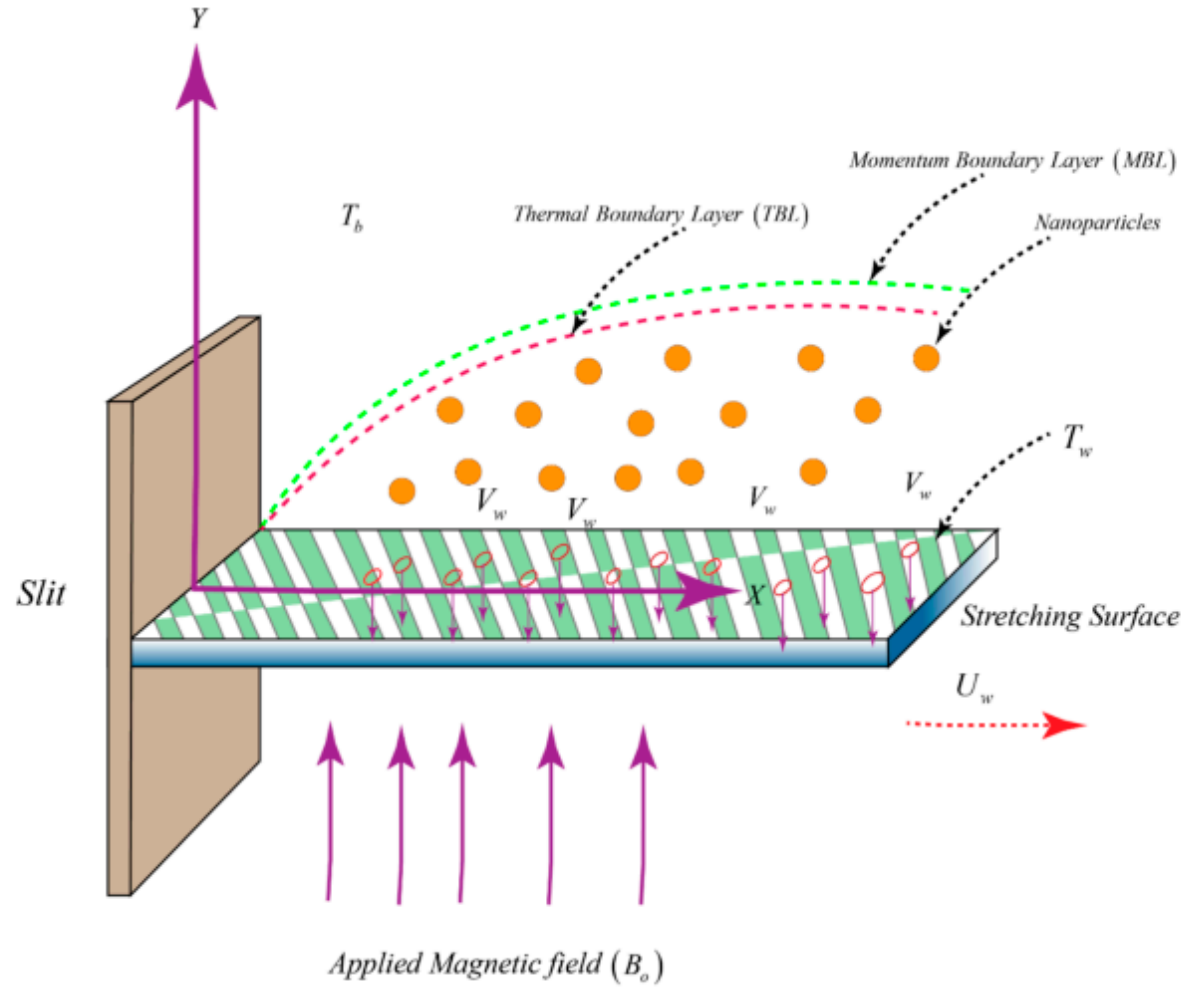

Figure 1. Physical flow model and coordinate system.

Table 1. Effective thermophysical properties of nanofluid [47-52].

\begin{tabular}{ccc}
\hline Thermophysical Property of Nanofluid & Symbol & Defined \\
\hline Thermal conductivity & $k_{n f}$ & $\begin{array}{c}k_{n f}=\frac{\left(k_{s}+2 k_{b f}\right)-2 \phi\left(k_{b f}-k_{s}\right)}{\left(k_{s}+2 k_{b f}\right)+\phi\left(k_{b f}-k_{s}\right)} k_{b f} \\
\text { here, } \phi \text { represents sold volume fraction } \\
\text { of nanoparticles. }\end{array}$ \\
\hline Viscosity & $\mu_{n f}$ & $\mu_{n f}=\frac{\mu_{b f}}{(1-\phi)^{2.5}}$ \\
\hline Electric conductivity & $\sigma_{n f}$ & $\sigma_{n f}=1+\frac{3\left(\frac{\sigma_{s}}{\sigma_{b f}}-1\right) \phi}{\left(\frac{\sigma_{s}}{\sigma_{b f}}+2\right)-\left(\frac{\sigma_{s}}{\sigma_{b f}}-1\right) \phi} \sigma_{b f}$ \\
\hline Heat capacitance & $\left(\rho C_{p}\right)_{n f}$ & $\left(\rho C_{p}\right)_{n f}=(1-\phi)\left(\rho C_{p}\right)_{b f}+\phi\left(\rho c_{p}\right)_{s}$ \\
\hline Density & $\rho_{n f}$ & $\rho_{n f}=(1-\phi) \rho_{b f}+\phi \rho_{s}$ \\
\hline
\end{tabular}


Table 2. Thermophysical properties of $\mathrm{CuO}, \mathrm{Fe}_{3} \mathrm{O}_{4}$, and working fluid $\left(\mathrm{H}_{2} \mathrm{O}\right)$.

\begin{tabular}{cccc}
\hline Physical Properties & $\mathbf{H}_{2} \mathbf{O}$ & $\mathbf{C u O}$ & $\mathbf{F e}_{3} \mathbf{O}_{4}$ \\
\hline$C_{p}(\mathrm{~J} / \mathrm{kgK})$ & 4179 & 531.8 & 670 \\
\hline$k(\mathrm{~W} / \mathrm{mK})$ & 0.613 & 76.5 & 6.0 \\
\hline$\rho\left(\mathrm{kg} / \mathrm{m}^{3}\right)$ & 997.1 & 6320 & 5200 \\
\hline$\sigma\left(\mathrm{S} \times \mathrm{m}^{-1}\right)$ & 5180 & $2.7 \times 10^{-8}$ & 25,000 \\
\hline $\operatorname{Pr}(-)$ & 6.8 & - & -
\end{tabular}

\section{Solution Methodology}

\subsection{Closed-Form Solution of Momentum Balance Equation}

The closed-form exact solution of Equation (6) with associated boundary conditions of Equation (8) is supposed as follows:

$$
f(\eta)=C_{1}+C_{2} e^{-\beta \eta}, \beta>0
$$

Using the first two boundary conditions defined in Equation (8), the computed arbitrary constants $C_{1}$ and $C_{2}$ are

$$
C_{1}=S+\frac{1}{\beta}, C_{2}=-\frac{1}{\beta}
$$

Putting Equation (11) into Equation (10), we get

$$
f(\eta)=S+\frac{1}{\beta}\left(1-e^{-\beta \eta}\right)
$$

The above closed-form solution trivially satisfies the far-field boundary condition as defined in Equation (8) for $\beta>0$. To find $\beta$, we insert Equation (12) into Equation (6) and get

$$
\frac{G_{1}}{G_{0}} \beta^{2}-S \beta-1-\frac{G_{3}}{G_{0}} M^{2}=0
$$

By solving the above equation, we have

$$
\beta=G_{o}\left(\frac{S+\sqrt{S^{2}+4 \frac{G_{1}}{G_{o}}\left(1+\frac{G_{3}}{G_{o}} M^{2}\right)}}{2 G_{1}}\right)>0 .
$$

The closed-form solution of the boundary value problem (Equations (6) and (7)) is given by

$$
f(\eta)=S+\frac{2 G_{1}}{G_{o}\left(S+\sqrt{S^{2}+4 \frac{G_{1}}{G_{o}}\left(1+\frac{G_{3}}{G_{o}} M^{2}\right)}\right)}\left(1-e^{-G_{o}\left(\frac{\left.S+\sqrt{s^{2}+4 \frac{G_{1}}{G_{o}}\left(1+\frac{G_{3}}{G_{0}} M^{2}\right)}\right)}{2 G_{1}}\right)}\right)
$$

\subsection{Solution of Energy Balance Equation via Laplace Transform}

Equation (7) is decoupled from Equation (6) by substituting Equation (12) into Equation (7) as follows:

$$
\frac{G_{5}}{G_{4}} \theta^{\prime \prime}+\frac{G_{1}}{G_{4}} E c \operatorname{Pr} \beta^{2} e^{-2 \beta \eta}+\operatorname{Pr}\left(S+\frac{1}{\beta}\left(1-e^{-\beta \eta}\right)\right) \theta^{\prime}+\frac{G_{3}}{G_{4}} E c M^{2} \operatorname{Pr} e^{-2 \beta \eta}-2 \operatorname{Pr} \theta e^{-\beta \eta}=0
$$


To get rid of exponential coefficients, we define a new variable, $\xi$, as follows:

$$
\xi=\frac{\operatorname{Pr}}{\beta^{2}} e^{-\beta \eta}
$$

By utilizing the above transformation, Equation (7) and the related boundary conditions take the following form:

$$
\begin{gathered}
\xi \frac{d^{2} \theta}{d \xi^{2}}+\frac{d \theta}{d \xi}\left(K+\frac{\xi}{G}\right)+\xi L-2 \frac{\theta}{G}=0, \\
\theta\left(\frac{\operatorname{Pr}}{\beta^{2}}\right)=1, \theta(0)=0
\end{gathered}
$$

with

$$
K=1-\frac{\operatorname{Pr}(1+\beta S)}{G \beta^{2}}, L=\frac{E c \beta^{2}}{G \operatorname{Pr}}\left(\frac{G_{1}}{G_{4}} \beta^{2}+\frac{G_{3}}{G_{4}} M^{2}\right) \text { and } G=\frac{G_{5}}{G_{4}} .
$$

By employing Laplace transform on Equation (18) and then using Equation (19), we obtain

$$
\frac{d \Theta(\zeta)}{d \zeta}+\Theta(\zeta)\left[\frac{\zeta(2-K)+\frac{3}{G}}{\zeta\left(\zeta+\frac{1}{G}\right)}\right]=\frac{L}{\zeta^{3}\left(\zeta+\frac{1}{G}\right)}
$$

where $\Theta(\zeta)$ is the Laplace transform of the function $\theta(\xi)$. Equation (21) is a Leibnitz first-type linear equation with integrating factor

$$
e^{\int \frac{\zeta(2-K)+\frac{3}{G}}{\zeta\left(\zeta+\frac{1}{G}\right)} d \zeta}=\frac{\zeta^{3}}{(G \zeta+1)^{1+K}}
$$

Solving Equation (21) by utilizing Equation (22), we have

$$
\Theta(\zeta)=\frac{L}{\zeta^{3}(-K-1)}+c \frac{(G \zeta+1)^{K+1}}{\zeta^{3}}
$$

By taking Laplace inverse of Equation (23), we get

$$
\theta(\xi)=\frac{L \xi^{2}}{2(-K-1)}+\frac{c}{2 G^{-K-1} \Gamma(-K-1)}\left(\xi^{2} * \xi^{-2-K} \mathrm{e}^{\left(\frac{-\xi}{G}\right)}\right)
$$

Here, an asterisk $(*)$ indicates convolution and $\Gamma$ shows a gamma function. The convolution of two functions, $F(\xi)$ and $G(\xi)$, is defined as follows:

$$
F(\xi) * H(\xi)=\int_{0}^{\xi} F(\xi-\varepsilon) H(\varepsilon) d \varepsilon
$$

By taking $F(\xi)=\xi^{2}$ and $H(\xi)=e^{\frac{-\xi}{G}} \xi^{-K-2}$, Equation (24) takes the following form:

$$
\theta(\xi)=\frac{L \xi^{2}}{2(-K-1)}+\frac{c}{2 G^{-K-1} \Gamma(-K-1)} \int_{0}^{\xi}(\xi-\varepsilon)^{2} e^{\frac{-\varepsilon}{G}} \varepsilon^{-K-2} d \varepsilon
$$


By employing the transformation $\varepsilon=\xi u$, the above equation takes the following form:

$$
\theta(\xi)=-\frac{L \xi^{2}}{2(K+1)}+\frac{c \xi^{1-K}}{2 G^{-K-1} \Gamma(-K-1)} \int_{0}^{1}(1-u)^{2} e^{\frac{-u \xi}{G}} u^{-K-2} d u
$$

By utilizing the integral form of Kummer's confluent hypergeometric function, i.e., $M_{1,1}\left(-K-1 ;-K+2 ; \frac{-\xi}{G}\right)=\frac{\Gamma(2-K)}{2 \Gamma(-1-K)} \int_{0}^{1}(1-u)^{2} e^{\frac{-u \xi}{G}} u^{-K-2} d$, Equation (27) becomes

$$
\theta(\xi)=-\frac{L \xi^{2}}{2(K+1)}+\frac{c G^{K+1} \xi^{1-K}}{\Gamma(2-K)} M_{1,1}\left(-K-1 ;-K+2 ; \frac{-\xi}{G}\right)
$$

The boundary condition at the surface of the stretching surface $\theta(0)=0$ is satisfied identically. However, the constant of integration $c$ is obtained by using the far-field boundary condition $\theta\left(\xi=\frac{\mathrm{Pr}}{\beta^{2}}\right)=1$ and is given by

$$
c=\frac{\Gamma(2-m)\left(\frac{2(K+1)+L\left(\frac{\mathrm{Pr}}{\beta^{2}}\right)^{2}}{2(K+1)}\right)}{G^{K+1}\left(\frac{\mathrm{Pr}}{\beta^{2}}\right)^{1-K} M_{1,1}\left(-1-K ; 2-K ;-\frac{\mathrm{Pr}}{G \beta^{2}}\right)} .
$$

Finally, by inserting Equation (29) into Equation (28) and using the transformation $\xi=\frac{\operatorname{Pr}}{\beta^{2}} e^{-\beta \eta}$, we obtain the exact solution of the energy equation:

$$
\theta(\eta)=-\frac{1}{2} \frac{L}{(K+1)}\left(\frac{\operatorname{Pr} e^{-\beta \eta}}{\beta^{2}}\right)^{2}+\frac{\left(\frac{\operatorname{Pr} e^{-\beta \eta}}{\beta^{2}}\right)^{1-K} M_{1,1}\left(-1-K ; 2-K ;-\frac{\operatorname{Pr} e^{-\beta \eta}}{G \beta^{2}}\right)\left(1+\frac{L}{2(1+K)}\left(\frac{\operatorname{Pr}}{\beta^{2}}\right)^{2}\right)}{\left(\frac{\operatorname{Pr}}{\beta^{2}}\right)^{1-K} M_{1,1}\left(-K-1 ; 2-K ;-\frac{\operatorname{Pr}}{G \beta^{2}}\right)} .
$$

\section{Analysis of Entropy Generation}

The rate of entropy generation in the presence of heat dissipation phenomenon with magnetic heating is given by

$$
\dot{E}_{G e n}^{\prime \prime \prime}=\frac{k_{n f}}{T^{2}}\left(\frac{\partial T}{\partial Y}\right)^{2}+\frac{\mu_{n f}}{T}\left(\frac{\partial U}{\partial Y}\right)^{2}+\frac{\sigma_{n f} B_{o}^{2} U^{2}}{T},
$$

Using Equation (6), Equation (31) becomes

$$
\frac{\dot{E}_{G e n}^{\prime \prime \prime}}{\left(\dot{E}_{G e n}^{\prime \prime \prime}\right)_{0}}=N s=\underbrace{G_{5} \frac{\theta^{\prime 2}}{(\theta+\Lambda)^{2}}}_{N_{H}}+\underbrace{\frac{G_{1} \operatorname{Pr} E c f^{\prime \prime 2}}{(\theta+\Lambda)}}_{N_{F}}+G_{3} \underbrace{\frac{\operatorname{Pr} M^{2} E c f^{\prime 2}}{(\theta+\Lambda)}}_{N_{M}} \text {. }
$$

Here, $\left(\dot{E}_{G e n}^{\prime \prime \prime}\right)_{0}=\frac{k_{b f} U_{0}}{v_{b f}}$ indicates characteristic entropy generation; $N$ s indicates entropy production rate in dimensionless form; $\Lambda=\frac{T_{b}}{T_{w}-T_{b}}$ shows the temperature parameter; and $N_{H}, N_{F}$, and $N_{M}$ represent the dimensionless form of entropy generation due to heat transfer, viscous dissipation, and magnetic heating, respectively. 
By utilizing the obtained exact solutions, the three sources of entropy generation stated above take the following forms:

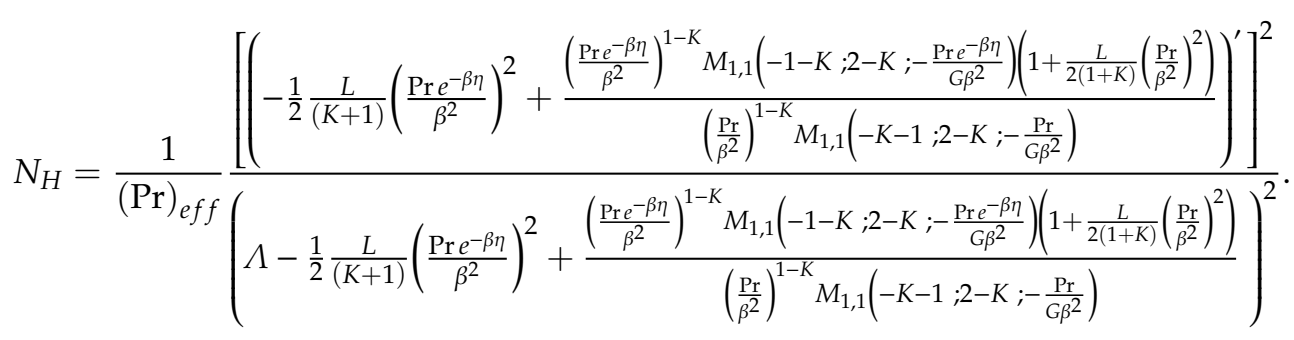

$$
\begin{aligned}
& N_{F}=\frac{\operatorname{EcPr}\left(\frac{-S+\sqrt{S^{2}+4 \frac{G_{1}}{G_{o}}\left(1+\frac{G_{3}}{G_{o}} M^{2}\right)}}{2 G_{1}} e^{-\eta\left(\frac{S+\sqrt{S^{2}+4 \frac{G_{1}}{G_{o}}\left(1+\frac{G_{3}}{G_{o}} M^{2}\right)} G_{o}}{2 G_{1}}\right)}\right)^{2} G^{3}{ }_{o}}{\left(\Lambda-\frac{1}{2} \frac{L}{(K+1)}\left(\frac{\operatorname{Pr} e^{-\beta \eta}}{\beta^{2}}\right)^{2}+\frac{\left(\frac{\operatorname{Pr} e^{-\beta \eta}}{\beta^{2}}\right)^{1-K} M_{1,1}\left(-1-K ; 2-K ;-\frac{\operatorname{Pr} e^{-\beta \eta}}{G \beta^{2}}\right)\left(1+\frac{L}{2(1+K)}\left(\frac{\operatorname{Pr}}{\beta^{2}}\right)^{2}\right)}{\left(\frac{\operatorname{Pr}}{\beta^{2}}\right)^{1-K} M_{1,1}\left(-K-1 ; 2-K ;-\frac{\operatorname{Pr}}{G \beta^{2}}\right)}\right.} .
\end{aligned}
$$

and

$$
N_{H}=\frac{M^{2} E c \operatorname{Pr}\left(e^{-\eta\left(\frac{S+\sqrt{S^{2}+4 \frac{G_{1}}{G_{o}}\left(1+\frac{G_{3}}{G_{0}} M^{2}\right) G_{o}}}{2 G_{1}}\right)}\right)^{2}}{\left(\Lambda-\frac{1}{2} \frac{L}{(K+1)}\left(\frac{\operatorname{Pr} e^{-\beta \eta}}{\beta^{2}}\right)^{2}+\frac{\left(\frac{\operatorname{Pr} e^{-\beta \eta}}{\beta^{2}}\right)^{1-K} M_{1,1}\left(-1-K ; 2-K ;-\frac{\operatorname{Pr} e^{-\beta \eta}}{G \beta^{2}}\right)\left(1+\frac{L}{2(1+K)}\left(\frac{\operatorname{Pr}}{\beta^{2}}\right)^{2}\right)}{\left(\frac{\operatorname{Pr}}{\beta^{2}}\right)^{1-K} M_{1,1}\left(-K-1 ; 2-K ;-\frac{\operatorname{Pr}}{G \beta^{2}}\right)}\right.} .
$$

\subsection{Bejan Number}

To compare the spatial distribution of entropy generation in a flow field due to various sources, an irreversibility ratio parameter known as Bejan number $(B e)$ is defined as given below

$$
B e=\frac{\frac{k_{n f}}{T^{2}}\left(\frac{\partial T}{\partial Y}\right)^{2} \Rightarrow(\text { Entropy generation due to heat transfer })}{\left(\frac{k_{n f}}{T^{2}}\left(\frac{\partial T}{\partial Y}\right)^{2}+\frac{\mu_{n f}}{T}\left(\frac{\partial U}{\partial Y}\right)^{2}+\frac{\sigma_{n f} B_{o}^{2} U^{2}}{T}\right) \Rightarrow(\text { Total entropy generation })}
$$

After the utilization of similarity variables, Equation (36) takes the following form:

$$
B e=\frac{G_{5} \frac{\theta^{\prime 2}}{(\theta+\Lambda)^{2}} \Rightarrow N_{H}}{\left(G_{5} \frac{\theta^{\prime 2}}{(\theta+\Lambda)^{2}}+\frac{G_{1} \operatorname{Pr} E c f^{\prime \prime 2}}{(\theta+\Lambda)}+G_{3} \frac{\operatorname{Pr} M^{2} E c f^{\prime 2}}{(\theta+\Lambda)}\right) \Rightarrow\left(N_{H}+N_{F}+N_{M}\right)}
$$




\section{Results and Discussion}

The nondimensional complicated differential equations (momentum and energy equations) are solved by taking into consideration the exponential form solution and the Laplace transform. The exact expressions are obtained for entropy generation via heat transfer, magnetic heating, and frictional heating. The dimensionless entropy production $(N s)$, velocity $f^{\prime}(\eta)$, and temperature $\theta(\eta)$ are plotted against $\eta$ by taking various values of relevant parameters. The Bejan number $(B e)$ profile is also plotted against the similarity variable $\eta$ by considering different values of the relevant embedded parameters. All the figures are plotted by taking water as a base fluid. Nanoparticles of $\mathrm{Fe}_{3} \mathrm{O}_{4} / \mathrm{CuO}$ are dispersed in $\mathrm{H}_{2} \mathrm{O}$.

Figure 2a demonstrates the impact of mass suction $(S)$ on the velocity of $\mathrm{Fe}_{3} \mathrm{O}_{4}-\mathrm{H}_{2} \mathrm{O}$ and $\mathrm{CuO}-\mathrm{H}_{2} \mathrm{O}$ nanoliquids. The decrement in motion is seen for both $\mathrm{Fe}_{3} \mathrm{O}_{4}-\mathrm{H}_{2} \mathrm{O}$ and $\mathrm{CuO}-\mathrm{H}_{2} \mathrm{O}$ nanoliquids with increasing $(S)$. For a fixed value of $(S)$, the velocity of the $\mathrm{CuO}-\mathrm{H}_{2} \mathrm{O}$ nanoliquid is higher than the velocity of the $\mathrm{Fe}_{3} \mathrm{O}_{4}-\mathrm{H}_{2} \mathrm{O}$ nanoliquid. Furthermore, the velocity of both nanoliquids satisfies the boundary condition at $\eta \rightarrow \infty$ asymptotically. Figure $2 \mathrm{~b}$ demonstrates the influence of the magnetic parameter $\left(M^{2}\right)$ on $f^{\prime}(\eta)$. It is seen that $f^{\prime}(\eta)$ reduces as $M^{2}$ increases. It is a well-known fact that the Lorentz force acts as a decelerating force for fluid flow and varies directly as $M^{2}$ increases. Due to this fact, $f^{\prime}(\eta)$ varies inversely with $M^{2}$. Furthermore, the velocity of the $\mathrm{Fe}_{3} \mathrm{O}_{4}-\mathrm{H}_{2} \mathrm{O}$ nanoliquid is lower than the velocity of the $\mathrm{CuO}-\mathrm{H}_{2} \mathrm{O}$ nanoliquid, and this is because of the low density of $\mathrm{Fe}_{3} \mathrm{O}_{4}-\mathrm{H}_{2} \mathrm{O}$ compared to $\mathrm{CuO}-\mathrm{H}_{2} \mathrm{O}$. Figure 3 a shows the variation of temperature $\theta(\eta)$ with $S$ by taking $M=1, \phi=0.1, E c=0.5$, and $\operatorname{Pr}=6.8$. The temperature drop is observed with increasing values of $S$. The width of the thermal boundary layer (TBL) of the $\mathrm{Fe}_{3} \mathrm{O}_{4}-\mathrm{H}_{2} \mathrm{O}$ nanoliquid is greater than that of the $\mathrm{CuO}-\mathrm{H}_{2} \mathrm{O}$ nanoliquid. Furthermore, the difference in TBL thickness reduces as $S$ increases. The effects of $M^{2}$ on temperature $\theta(\eta)$ are presented in Figure $3 b$. It is seen that $\theta(\eta)$ is augmented as $M^{2}$ increases. The rising behavior of temperature is because of magnetic heating. The effective thermal conductivity of nanoliquids is directly related to the solid volume fraction of nanoparticles $(\phi)$, and this augments the temperature of nanoliquids, as shown in Figure 3c. Furthermore, the width of TBL is smaller for base fluid $\mathrm{H}_{2} \mathrm{O}$ and larger for $\mathrm{Fe}_{3} \mathrm{O}_{4}-\mathrm{H}_{2} \mathrm{O}$. This is due to the low thermal conductivity of water and the high effective thermal conductivity of the $\mathrm{Fe}_{3} \mathrm{O}_{4}-\mathrm{H}_{2} \mathrm{O}$ nanoliquid. Figure $3 \mathrm{~d}$ reveals the influence of the Eckert number $(E c)$ on $\theta(\eta)$. It is found that increasing Ec leads to a rising temperature. The dissipation function implies that frictional heating varies directly with velocity gradients, and the velocity gradients are high in the vicinity of stretching surface. Due to this fact, the temperature shoots up suddenly, resulting in a higher Eckert number in the vicinity of the stretching plate, as shown in Figure 3d.

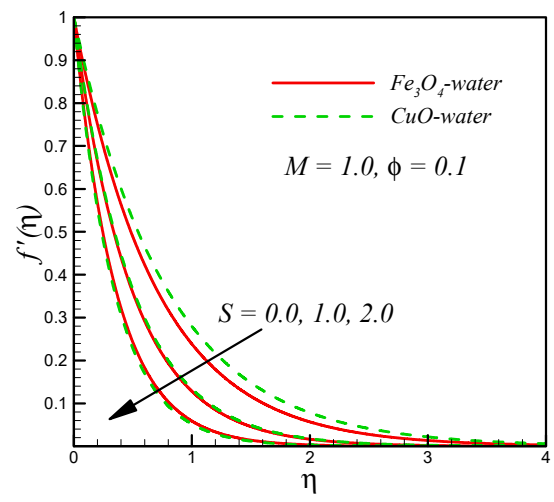

(a)

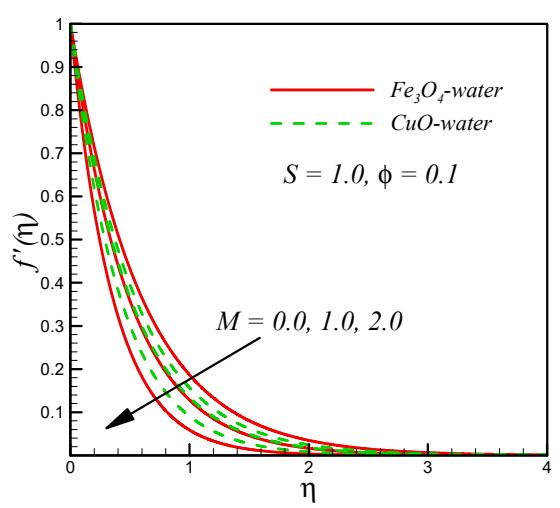

(b)

Figure 2. Variation of the velocity profile $f^{\prime}(\eta)$ with (a) $S$ and (b) $M$. 


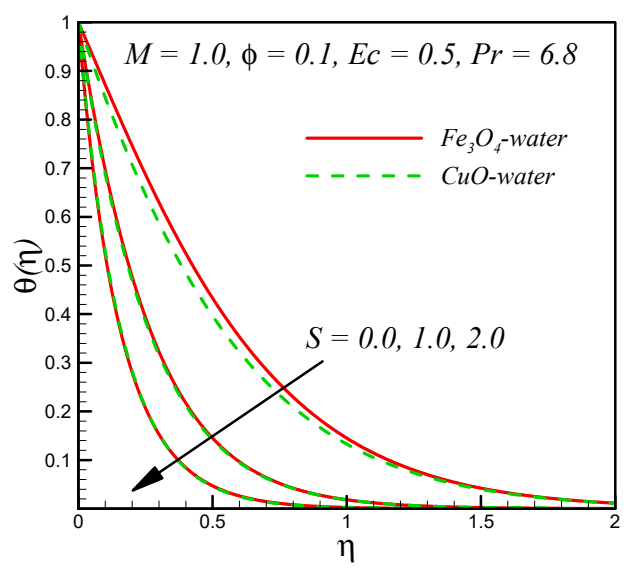

(a)

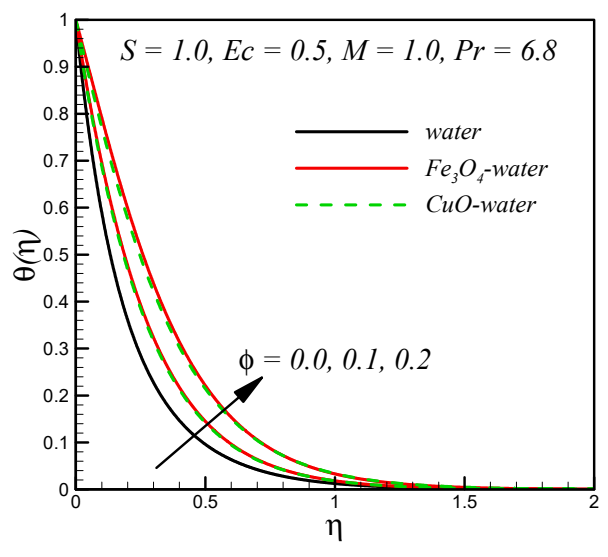

(c)

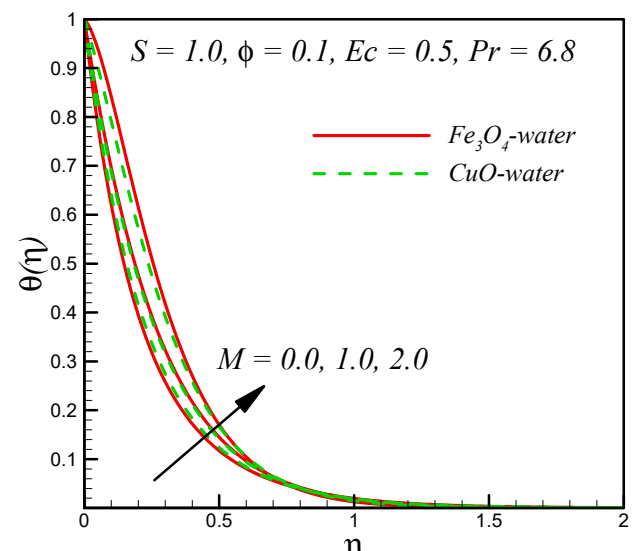

(b)

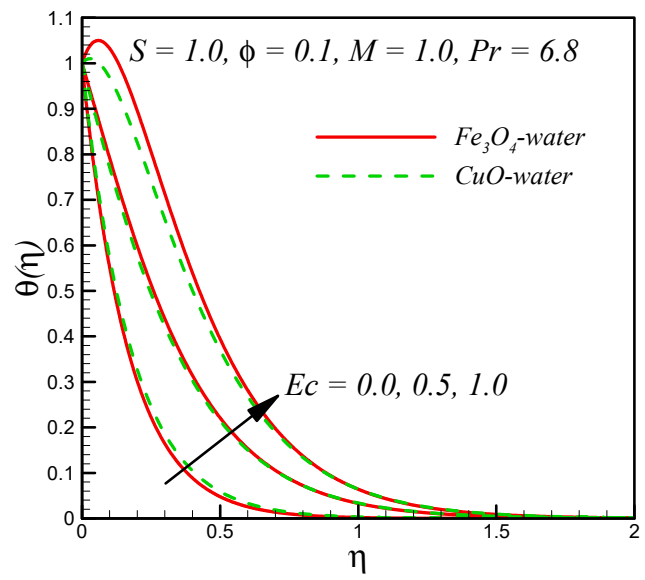

(d)

Figure 3. Variation of the temperature profile $\theta(\eta)$ with (a) $S$, (b) $M,(\mathbf{c}) \phi$, and (d) Ec.

Figure 4a portrays the effects of the Eckert number $(E c)$ on the entropy generation number $(N s)$. As seen from the plot, $N s$ is directly related to the Eckert number. This happens since frictional heating increases with the increasing Eckert number. The entropy generation in the $\mathrm{Fe}_{3} \mathrm{O}_{4}-\mathrm{H}_{2} \mathrm{O}$ nanoliquid than that in the $\mathrm{CuO}-\mathrm{H}_{2} \mathrm{O}$ nanoliquid. Furthermore, the surface of the solid boundary is the region where maximum entropy is generated. The features of mass suction $(S)$ on $N s$ are revealed in Figure $4 \mathrm{~b}$. As $S$ increases, entropy generation rises at the solid wall and its vicinity, but the opposite trend is observed to start at a certain distance away from the boundary. Furthermore, entropy generation is higher in the $\mathrm{Fe}_{3} \mathrm{O}_{4}-\mathrm{H}_{2} \mathrm{O}$ nanoliquid at the solid boundary and its neighborhood as compared to the $\mathrm{CuO}-\mathrm{H}_{2} \mathrm{O}$ nanoliquid, but the trend becomes the opposite at a certain distance from the boundary. The nature of entropy generation $(\mathrm{Ns})$ with disparate values of the solid volume fraction of nanoparticles $(\phi)$ is shown in Figure 4c. From this plot, it can be seen that $N s$ increases as $\phi$ increases. This increase in Ns is due to the boost of heat transfer with increasing $\phi$. It is well known that the magnetic force is nonconservative. The entropy generation is directly related to the nonconservative forces, and this fact is depicted in Figure $4 \mathrm{~d}$. The variations of $N s$ with temperature difference function $(\Lambda)$ are presented in Figure 4e. The Ns decreases with increasing values of $\Lambda$. Figure 5 a shows that the Bejan number $(\mathrm{Be})$ has a maximum value at the surface of the stretching boundary for a nonzero suction parameter $(S)$. In the case of an impermeable stretching boundary, the entropy generation in the $\mathrm{Fe}_{3} \mathrm{O}_{4}-\mathrm{H}_{2} \mathrm{O}$ nanoliquid is due to dissipative forces (viscous and magnetic) near and on the boundary, which are high in comparison to those of the $\mathrm{CuO}-\mathrm{H}_{2} \mathrm{O}$ nanoliquid. An opposite trend is observed to start at a certain vertical distance from the stretching surface. In the case of $S>0$, the entropy generation on the stretching surface and inside the boundary layer due to magnetic and 
viscous heating is more dominant in the $\mathrm{Fe}_{3} \mathrm{O}_{4}-\mathrm{H}_{2} \mathrm{O}$ nanoliquid as compared to the $\mathrm{CuO}-\mathrm{H}_{2} \mathrm{O}$ nanoliquid. It is noticed from Figure $5 \mathrm{~b}$ that $B e$ is directly related to the solid volume fraction $(\phi)$ in the region away from the stretching boundary. In the vicinity of an elastic boundary, the opposite trend is observed. From Figure 5c, it can be seen that the Bejan number diminishes as $\Lambda$ increases. Furthermore, the entropy generation by nonconservative forces (viscous and magnetic) is higher in the $\mathrm{Fe}_{3} \mathrm{O}_{4}-\mathrm{H}_{2} \mathrm{O}$ nanoliquid than in the $\mathrm{CuO}-\mathrm{H}_{2} \mathrm{O}$ nanoliquid.

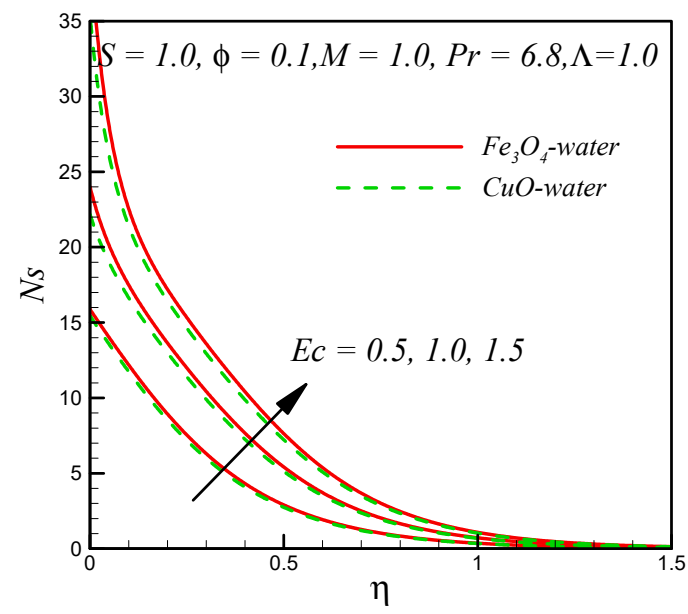

(a)

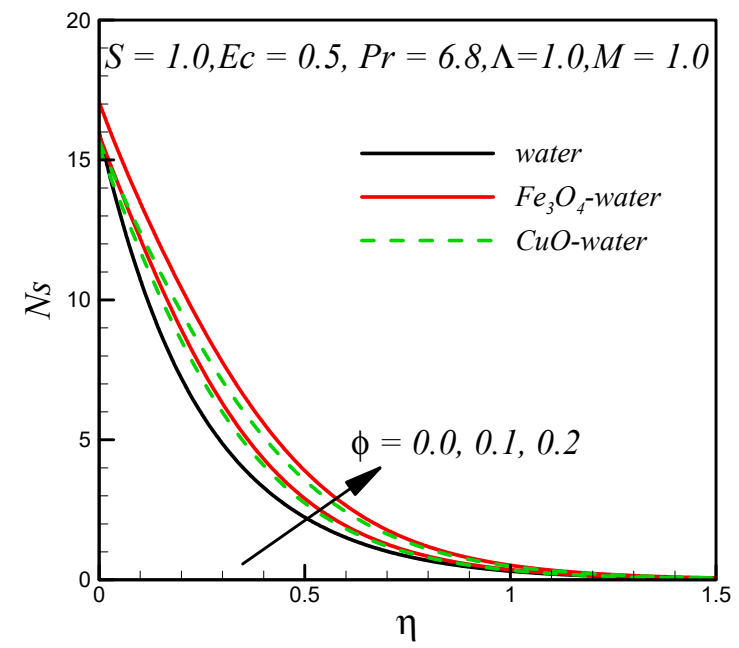

(c)

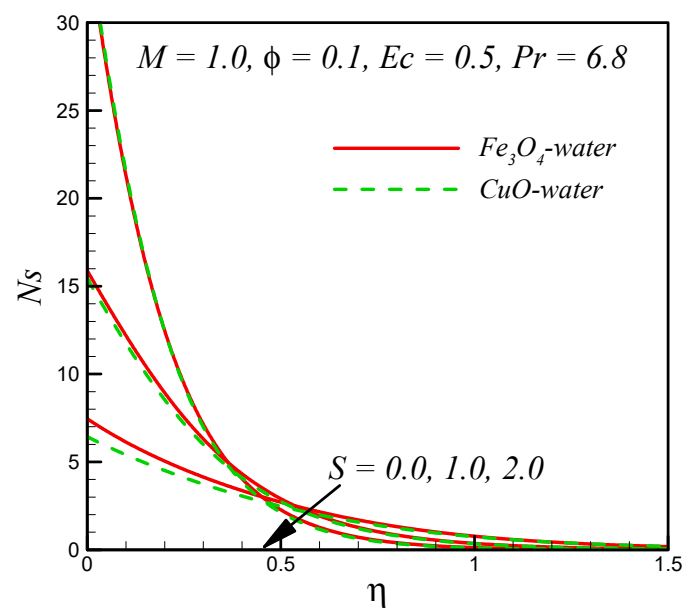

(b)

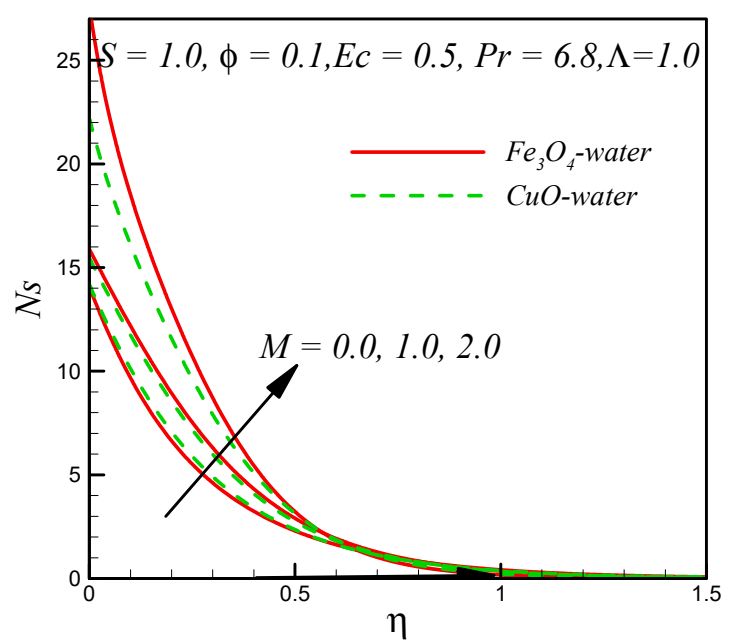

(d)

Figure 4. Cont. 


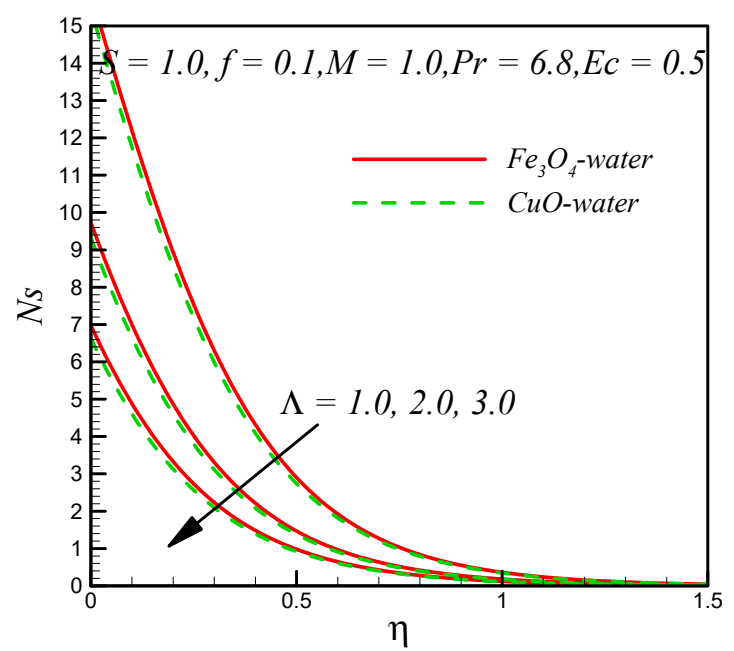

(e)

Figure 4. Variation of entropy generation profile $N s(\eta)$ with (a) $E c,(\mathbf{b}) S,(\mathbf{c}) \phi,(\mathbf{d}) M$, and (e) $\Lambda$.

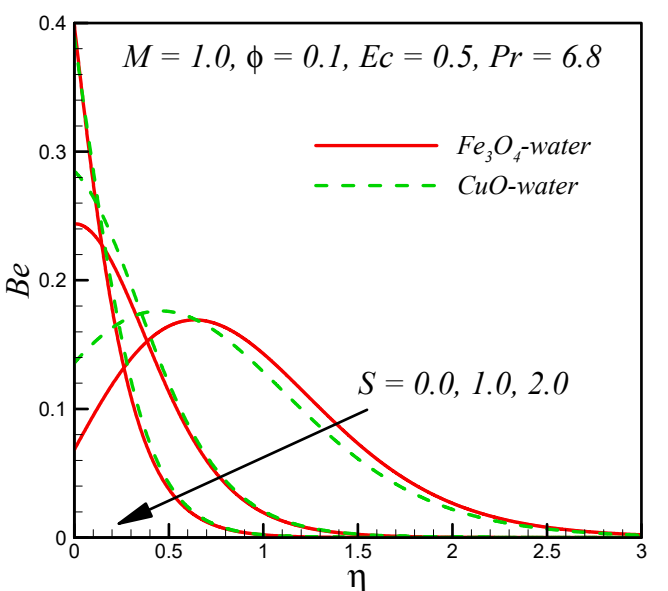

(a)

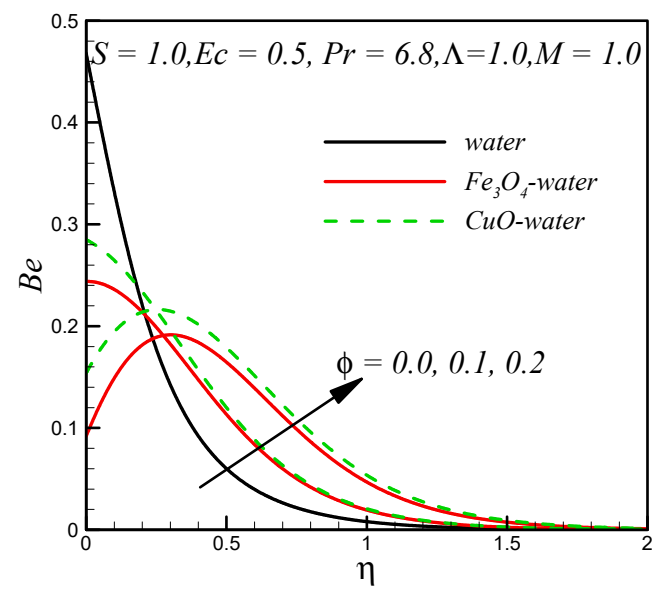

(b)

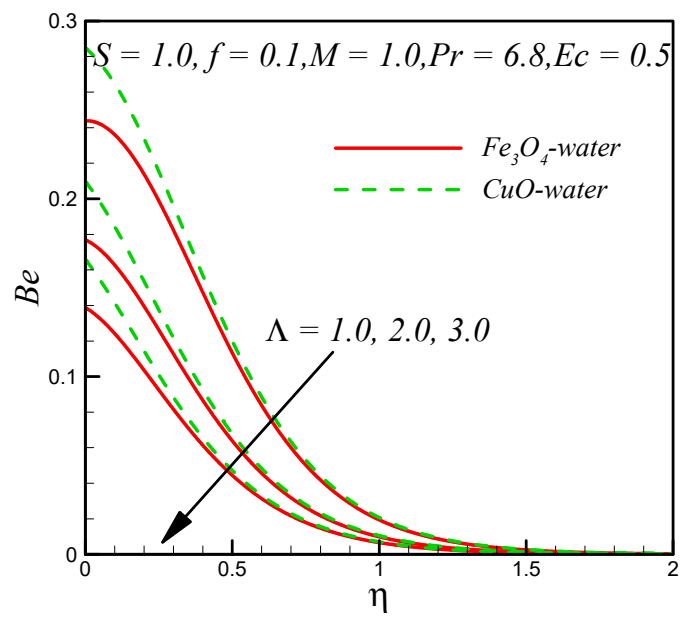

(c)

Figure 5. Variation of Bejan number $B e(\eta)$ with (a) $S$, (b) $M$ and (c) $\phi$. 


\section{Concluding Remarks}

In this study, we investigated flow, heat transfer, and entropy production in a dissipative nanofluid flow under the influence of a magnetic field. The following findings can be drawn from the exact results:

- The decrement in motion is seen for both $\mathrm{Fe}_{3} \mathrm{O}_{4}-\mathrm{H}_{2} \mathrm{O}$ and $\mathrm{CuO}-\mathrm{H}_{2} \mathrm{O}$ nanofluids with increasing $S$ and $M^{2}$.

- The velocity of the $\mathrm{CuO}-\mathrm{H}_{2} \mathrm{O}$ nanofluid is higher than that of the $\mathrm{Fe}_{3} \mathrm{O}_{4}-\mathrm{H}_{2} \mathrm{O}$ nanofluid.

- The temperature $\theta(\eta)$ is observed to decrease with increasing values of $S$.

- The temperature $\theta(\eta)$ increases as $M^{2}, \phi$, and $E c$ increase.

- The thermal boundary layer (TBL) width of the $\mathrm{Fe}_{3} \mathrm{O}_{4}-\mathrm{H}_{2} \mathrm{O}$ nanoliquid is greater than that of the $\mathrm{CuO}-\mathrm{H}_{2} \mathrm{O}$ nanoliquid.

- The entropy generation number $(N s)$ is directly related to the Eckert number $(E c)$ and solid volume fraction $(\phi)$.

- Entropy generation (Ns) by nonconservative forces is higher in the $\mathrm{Fe}_{3} \mathrm{O}_{4}-\mathrm{H}_{2} \mathrm{O}$ nanoliquid than in the $\mathrm{CuO}-\mathrm{H}_{2} \mathrm{O}$ nanoliquid.

Author Contributions: M.I.A. and M.Q. formulated the problem. D.L. and U.A. solved the problem. U.F. and M.I.A. computed the results. All the authors equally contributed in writing and proofreading the paper. All authors have read and agreed to the published version of the manuscript.

Funding: This work was supported by the China Post-doctoral science foundation, China (Grant No. 2018M632237).

Acknowledgments: The authors would like to acknowledge the Department of Mathematics, Faculty of Science, Jiangsu University, Zhenjiang China for technical support.

Conflicts of Interest: The authors declare no conflict of interest.

\section{Nomenclature}

\begin{tabular}{|c|c|c|}
\hline$C_{0}$ & $\left(K L^{-2}\right)$ & Dimensional constant \\
\hline $\mathrm{Be}$ & (Dimensionless) & Bejan number \\
\hline$B_{0}$ & $\left(M T^{-2} I^{-1}\right)$ & The applied magnetic field. ("I" shows electric current) \\
\hline$\left(C_{p}\right)_{b f}$ & $\left(L^{2} T^{-2} K^{-1}\right)$ & Specific heat at a constant pressure of a base fluid \\
\hline$\left(C_{p}\right)_{n f}$ & $\left(L^{2} T^{-2} K^{-1}\right)$ & Specific heat at a constant pressure of nanofluid \\
\hline Ec & (Dimensionless) & Eckert number \\
\hline$f(\eta)$ & (Dimensionless) & Velocity normal to the solid surface \\
\hline$f^{\prime}(\eta)$ & (Dimensionless) & Velocity along the solid surface \\
\hline$\vec{j}$ & $L^{-2} I$ & Current density \\
\hline$k_{n f}$ & $\left(M L T^{-3} K^{-1}\right)$ & Thermal conductivity of nanofluid \\
\hline$k_{b f}$ & $\left(M L T^{-3} K^{-1}\right)$ & Thermal conductivity of the base fluid \\
\hline$k_{s}$ & $\left(M L T^{-3} K^{-1}\right)$ & Thermal conductivity of nanoparticle \\
\hline$M^{2}$ & (Dimensionless) & Magnetic parameter \\
\hline$N_{H}$ & (Dimensionless) & Entropy generation due to heat transfer \\
\hline$N_{F}$ & (Dimensionless) & Entropy generation due to viscous dissipation \\
\hline$N_{M}$ & (Dimensionless) & Entropy generation due to the magnetic field \\
\hline$N_{S}$ & (Dimensionless) & Entropy generation number \\
\hline $\operatorname{Pr}$ & (Dimensionless) & Prandtl number \\
\hline$S$ & (Dimensionless) & Mass transfer parameter \\
\hline$\dot{E}_{G e n}^{\prime \prime \prime}$ & $\left(M L^{-1} K^{-1} T^{-3}\right)$ & Rate of volumetric entropy generation \\
\hline$\left(\dot{E}_{G e n}^{\prime \prime \prime}\right)_{0}$ & $\left(M L^{-1} K^{-1} T^{-3}\right)$ & Characteristic entropy generation \\
\hline$T$ & $(K)$ & The temperature inside the boundary layer \\
\hline
\end{tabular}




$\begin{array}{ll}T_{w w}(x) & (K) \\ T_{b} & (K) \\ U_{w}(x) & \left(L T^{-1}\right) \\ U & \left(L T^{-1}\right) \\ U_{o} & \left(T^{-1}\right) \\ V & \left(L T^{-1}\right) \\ V_{w} & \left(L T^{-1}\right) \\ X, Y & (L)\end{array}$

\section{Greek Symbols}

$\begin{array}{ll}\eta & \text { (Dimensionless) } \\ \mu_{b f} & \left(M L^{-1} T^{-1}\right) \\ \mu_{n f} & \left(M L^{-1} T^{-1}\right) \\ v_{n f} & \left(L^{2} T^{-1}\right) \\ \rho_{n f} & \left(M L^{-3}\right) \\ \rho_{b f} & \left(M L^{-3}\right) \\ \rho_{s} & \left(M L^{-3}\right) \\ \sigma_{n f} & \left(M^{-1} L^{-3} T^{3} I^{2}\right) \\ \sigma_{b f} & \left(M^{-1} L^{-3} T^{3} I^{2}\right) \\ \sigma_{s} & \left(M^{-1} L^{-3} T^{3} I^{2}\right) \\ \theta(\eta) & \text { (Dimensionless) } \\ \phi & \text { (Dimensionless) } \\ \Lambda & \text { (Dimensionless) }\end{array}$

The temperature at the solid boundary

The temperature of fluid outside the thermal boundary layer

The velocity of a stretching sheet

Velocity component along the surface of the solid body

Constant

Velocity component normal to the surface of the solid body

Normal velocity component at the boundary

Cartesian coordinates

Similarity variable

Dynamic viscosity of a base fluid

Dynamic viscosity of nanofluid

Kinematic viscosity of nanofluid

Nanofluid density

The density of a base fluid

Density of nanoparticles

Electric conductivity

The electric conductivity of a base fluid

The electric conductivity of nanoparticle

Temperature

The solid volume fraction of nanoparticles

Temperature difference parameter

\section{References}

1. Wang, C.Y. Exact solutions of the steady-state Navier-Stockes equations. Annu. Rev. Fluid Mech. 1991, 23, 159-177. [CrossRef]

2. Hui, W.H. Exact solutions of the unsteady two-dimensional Navier-Stokes equations. J. Appl. Math. Phys. 1987, 38, 689-702. [CrossRef]

3. Polyanin, A.D. Exact solutions to the Navier-Stokes equations with generalized separation of variables. Dokl. Phys. 2001, 46, 726-731. [CrossRef]

4. Al-Mdallal, Q.M. A new family of exact solutions to the unsteady Navier-Stokes equations using canonical transformation with complex coefficients. Appl. Math. Comput. 2008, 196, 303-308. [CrossRef]

5. Daly, E.; Basser, H.; Rudman, M. Exact solutions of the Navier-Stokes equations generalized for flow in porous media. Eur. Phys. J. Plus 2018, 133, 173. [CrossRef]

6. Crane, L.J. Flow past a stretching plate. Zeitschrift für Angewandte Mathematik und Physik 1970, 4, 645-647. [CrossRef]

7. Fang, T.; Zhang, J.; Yao, S. Slip MHD viscous flow over a stretching sheet-An exact solution. Commun. Nonlinear Sci. Numer. Simul. 2009, 14, 3731-3737. [CrossRef]

8. Fang, T.; Zhang, J. Closed-form exact solutions of MHD viscous flow over a shrinking sheet. Commun. Nonlinear Sci. Numer. Simul. 2009, 14, 2853-2857. [CrossRef]

9. Liu, I.-C. Exact Solutions for a Fluid-Saturated Porous Medium with Heat and Mass Transfer. J. Mech. 2011, 21, 57-62. [CrossRef]

10. Turkyilmazoglu, M. Mixed convection flow of magnetohydrodynamic micropolar fluid due to a porous heated/cooled deformable plate: Exact solutions. Int. J. Heat Mass Transf. 2017, 106, 127-134. [CrossRef]

11. Khan, Z.H.; Qasim, M.; Ishfaq, N.; Khan, W.A. Dual Solutions of MHD Boundary Layer Flow of a Micropolar Fluid with Weak Concentration over a Stretching/Shrinking Sheet. Commun. Theor. Phys. 2017, 67, 449. [CrossRef]

12. Bejan, A. A Study of Entropy Generation in Fundamental Convective Heat Transfer. J. Heat Transf. 1979, 101, 718-725. [CrossRef] 
13. Bejan, A. The thermodynamic design of heat and mass transfer processes and devices. Int. J. Heat Fluid Flow 1987, 8, 258-276. [CrossRef]

14. Butt, A.S.; Ali, A.; Mehmood, A. Entropy analysis in MHD nanofluid flow near a convectively heated stretching surface. Int. J. Exergy 2016, 20, 318-342. [CrossRef]

15. Das, S.; Chakraborty, S.; Jana, R.N.; Makinde, O.D. Entropy analysis of unsteady magneto-nanofluid flow past accelerating stretching sheet with convective boundary condition. Appl. Math. Mech. 2015, 36, 1593-1610. [CrossRef]

16. Hakeem, A.K.A.; Govindaraju, M.; Ganga, B.; Kayalvizhi, M. Second law analysis for radiative MHD slip flow of a nanofluid over a stretching sheet with non-uniform heat source effect. Sci. Iran. 2016, 23, 1524-1538. [CrossRef]

17. Rashidi, M.M.; Freidoonimehr, N. Analysis of Entropy Generation in MHD Stagnation-Point Flow in Porous Media with Heat Transfer. Int. J. Comput. Methods Eng. Sci. Mech. 2014, 15, 345-355. [CrossRef]

18. Makinde, O.D. Entropy analysis for MHD boundary layer flow and heat transfer over a flat plate with a convective surface boundary condition. Int. J. Exergy 2012, 10, 142. [CrossRef]

19. Butt, A.S.; Ali, A.; Mehmood, A. Numerical investigation of magnetic field effects on entropy generation in viscous flow over a stretching cylinder embedded in a porous medium. Energy 2016, 99, 237-249. [CrossRef]

20. Ding, H.; Li, Y.; Lakzian, E.; Wen, C.; Wang, C. Entropy generation and exergy destruction in condensing steam flow through turbine blade with surface roughness. Energy Convers. Manag. 2019, 196, 1089-1104. [CrossRef]

21. Al-Odat, M.Q.; Damseh, R.A.; Al-Nimr, M.A. Effect of Magnetic Field on Entropy Generation Due to Laminar Forced Convection Past a Horizontal Flat Plate. Entropy 2004, 4, 293-303. [CrossRef]

22. Rashidi, M.M.; Mohammadi, F.; Abbasbandy, S.; Alhuthali, M.S. Entropy Generation Analysis for Stagnation Point Flow in a Porous Medium over a Permeable Stretching Surface. J. Appl. Fluid Mech. 2015, 8, 753-765. [CrossRef]

23. Das, S.; Jana, R.N.; Makinde, O.D. Entropy generation in hydromagnetic and thermal boundary layer flow due to radial stretching sheet with Newtonian heating. J. Heat Mass Transf. Res. 2015, 2, 51-61.

24. Ajibade, A.O.; Jha, B.K.; Omame, A. Entropy generation under the effect of suction/injection. Appl. Math. Model. 2011, 35, 4630-4646. [CrossRef]

25. Govindaraju, M.; Ganga, B.; Hakeem, A.K.A. Second law analysis on radiative slip flow of nanofluid over a stretching sheet in the presence of lorentz force and heat generation/absorption. Front. Heat Mass Transf. 2017, 8, 1-8. [CrossRef]

26. Milanese, M.; Iacobazzi, F.; Colangelo, G.; Risi, A. An investigation of layering phenomenon at the liquid-solid interface in $\mathrm{Cu}$ and $\mathrm{CuO}$ based nanofluids. Int. J. Heat Mass Transf. 2016, 103, 564-571. [CrossRef]

27. Iacobazzi, F.; Milanese, M.; Colangelo, G.; Lomascolo, M.; Risi, A. An explanation of the $\mathrm{Al}_{2} \mathrm{O}_{3}$ nanofluid thermal conductivity based on the phonon theory of liquid. Energy 2016, 116, 786-794. [CrossRef]

28. Colangelo, G.; Milanese, M.; De Risi, A. Numerical simulation of thermal efficiency of an innovative $\mathrm{Al}_{2} \mathrm{O}_{3}$ nanofluid solar thermal collector: Influence of nanoparticles concentration. Therm. Sci. 2017, 21, 2769-2779. [CrossRef]

29. Colangelo, G.; Favale, E.; Milanese, M.; de Risi, A.; Laforgia, D. Cooling of electronic devices: Nanofluids contribution. Appl. Therm. Eng. 2017, 127, 421-435. [CrossRef]

30. Colangelo, G.; Favale, E.; Miglietta, P.; Milanese, M.; de Risi, M. Thermal conductivity, viscosity and stability of $\mathrm{Al}_{2} \mathrm{O}_{3}$-diathermic oil nanofluids for solar energy systems. Energy 2016, 95, 124-136. [CrossRef]

31. Colangelo, G.; Favale, E.; Milanese, M.; Starace, G.; De Risi, A. Experimental Measurements of $\mathrm{Al}_{2} \mathrm{O}_{3}$ and $\mathrm{CuO}$ Nanofluids Interaction with Microwaves. J. Energy Eng. 2017, 143, 04016045. [CrossRef]

32. Iacobazzi, F.; Milanese, M.; Colangelo, G.; de Risi, A. A critical analysis of clustering phenomenon in $\mathrm{Al}_{2} \mathrm{O}_{3}$ nanofluids. J. Therm. Anal. Calorim. 2018, 135, 371-377. [CrossRef]

33. Hsiao, K.-L. Stagnation electrical MHD nanofluid mixed convection with slip boundary on a stretching sheet. Appl. Therm. Eng. 2016, 98, 850-861. [CrossRef]

34. Ma, Y.; Mohebbi, R.; Rashidi, M.; Yang, Z.; Sheremet, M. Nanoliquid thermal convection in I-shaped multiple-pipe heat exchanger under magnetic field influence. Phys. A Stat. Mech. Its Appl. 2020, 550, 124028. [CrossRef] 
35. Wakif, A.; Chamkha, A.; Thumma, T.; Animasaun, I.L.; Sehaqui, R. Thermal radiation and surface roughness effects on the thermo-magneto-hydrodynamic stability of alumina-copper oxide hybrid nanofluids utilizing the generalized Buongiorno's nanofluid model. J. Therm. Anal. Calorim. 2020, 1-20. [CrossRef]

36. Hsiao, K.-L. Nanofluid flow with multimedia physical features for conjugate mixed convection and radiation. Comput. Fluids 2014, 104, 1-8. [CrossRef]

37. Ma, Y.; Mohebbi, R.; Rashidi, M.M.; Yang, Z. MHD convective heat transfer of Ag-MgO/water hybrid nanofluid in a channel with active heaters and coolers. Int. J. Heat Mass Transf. 2019, 137, 714-726. [CrossRef]

38. Prasad, K.V.; Vaidya, H.; Makinde, O.D.; Vajravelu, K.; Wakif, A.; Basha, H. Comprehensive examination of the three-dimensional rotating flow of a UCM nanoliquid over an exponentially stretchable convective surface utilizing the optimal homotopy analysis method. Front. Heat Mass Transf. 2020, 14. [CrossRef]

39. Gebhart, B. Effects of viscous dissipation in natural convection. J. Fluid Mech. 1962, 14, 225-232. [CrossRef]

40. Desale, S.; Pradhan, V.H. Numerical Solution of Boundary Layer Flow Equation with Viscous Dissipation Effect Along a Flat Plate with Variable Temperature. Procedia Eng. 2015, 127, 846-853. [CrossRef]

41. Vajravelu, K.; Hadjinicolaou, A. Heat transfer in a viscous fluid over a stretching sheet with viscous dissipation and internal heat generation. Int. Commun. Heat Mass Transf. 1993, 20, 417-430. [CrossRef]

42. Alsabery, A.; Saleh, H.; Hashim, I. Effects of Viscous Dissipation and Radiation on MHD Natural Convection in Oblique Porous Cavity with Constant Heat Flux. Adv. Appl. Math. Mech. 2017, 9, 463-484. [CrossRef]

43. Mohamed, M.K.A.; Sarif, N.M.; Noar, N.A.Z.M.; Salleh, M.Z.; Ishak, A. Viscous dissipation effect on the mixed convection boundary layer flow towards solid sphere. Trans. Sci. Technol. 2016, 3, 59-67.

44. Jamaludin, A.; Nazar, R.; Khan, I. AIP Conference Proceedings; Boundary Layer Flow and Heat Transfer in a Viscous Fluid Over a Stretching Sheet with Viscous Dissipation, Internal Heat Generation and Prescribed Heat Flux; AIP Publishing LLC: New York, NY, USA, 2017; Volume 1870, p. 040029. [CrossRef]

45. Makinde, O.D. Effects of viscous dissipation and Newtonian heating on boundary-layer flow of nanofluids over a flat plate. Int. J. Numer. Methods Heat Fluid Flow 2013, 23, 1291-1303. [CrossRef]

46. Motsumi, T.G.; Makinde, O.D. Effects of thermal radiation and viscous dissipation on boundary layer flow of nanofluids over a permeable moving flat plate. Phys. Scr. 2012, 86, 1-8. [CrossRef]

47. Minkowycz, W.J.; Sparrow, E.M.; Abraham, J.P. Nanoparticle Heat Transfer and Fluid Flow; CRC Press: Boca Raton, FL, USA, 2012.

48. Bianco, V.; Manca, O.; Nardini, S.; Vafai, K. Heat Transfer Enhancement of Nanofluids; CRC Press: Boca Raton, FL, USA, 2015.

49. Kleinstreuer, C.; Feng, Y. Experimental and Theoretical Studies of Nanofluid Thermal Conductivity Enhancement: A Review. Nanoscale Res. Lett. 2011, 6, 229. [CrossRef]

50. Bashirnezhad, K.; Bazri, S.; Safaei, M.R.; Goodarzi, M.; Dahari, M.; Mahian, O.; Dalkılıça, A.S.; Wongwises, S. Viscosity of nanofluids: A review of recent experimental studies. Int. Commun. Heat Mass Transf. 2016, 73, 114-123. [CrossRef]

51. Sheikholeslami, M. Nanofluid Heat and Mass Transfer in Engineering Problems; Intech Open: Rijeka, Croatia, 2017.

52. Sajid, M.U.; Ali, H.M. Recent advances in application of nanofluids in heat transfer devices: A critical review. Renew. Sustain. Energy Rev. 2019, 103, 556-592. [CrossRef]

Publisher's Note: MDPI stays neutral with regard to jurisdictional claims in published maps and institutional affiliations.

(C) 2020 by the authors. Licensee MDPI, Basel, Switzerland. This article is an open access article distributed under the terms and conditions of the Creative Commons Attribution (CC BY) license (http://creativecommons.org/licenses/by/4.0/). 